\title{
Arbor
}

\section{La realidad y el objeto: del Surrealismo al Pop Art}

\author{
Victor Nieto Alcaide
}

Arbor CLXV, 649 (Enero 2000), 51-58 pp.

La historiografía de las vanguardias ha planteado sistemáticamente como auténticas fracturas del devenir artístico el trauma producido por los dos conflictos mundiales de 1914-1918 y 1939-1945. Las dos guerras interrumpieron la actividad artística, dispersaron a los artistas y ejercieron una acción negativa para el desarrollo del arte. Sin embargo, esta acción no fue tan profunda como para determinar que lo que surgió después en las postguerras no tuviese nada que ver con el desarrollo artístico anterior. Es evidente que después de 1918 el Cubismo perdió su papel hegemónico en el panorama de la vanguardia y que el Futurismo vió agotada la acelera velocidad de sus provocaciones. Y no es menos cierto que, poco después de concluida la Primera Guerra mundial, el Surrealismo irrumpió como la tendencia protagonista de una vanguardia radical. Del mismo modo, el Surrealismo, tras la Segunda Guerra mundial se vió desplazado de su podio hegemónico por el Informalismo, tendencia que proponía el valor de la abstracción frente al valor de la recuperación del sistema de representación desarrollada durante casi veinte años por los surrealistas.

Sin embargo, estas fracturas históricas, jalones en la construcción y experimentación de la vanguardia, no fueron nunca una ruptura radical con todo lo anterior ni supusieron un volver a comenzar de cero. Con frecuencia fueron rupturas en las que permanecían muchos aspectos, especialmente desde un punto de vista conceptual e ideológico, que no habían sido desarrollados por las tendencias precedentes.

Es innegable la deuda de los pintores surrealistas con la pintura metafísica de Giorgio de Chirico y, sobre todo, con la ideología del antiideario Dada. Igualmente son claramente reconocibles las vinculaciones de la abstracción informalista con ciertos presupuestos ideo- 
lógicos y vitales del Surrealismo y con numerosos usos y dicciones del Expresionismo. Sin embargo, aunque la relación del Surrealismo con el Dada es algo reconocido de una forma unánime la aparición del Informalismo se ha cosiderado como la irrupción de una tendencia que partía de cero. Incluso, como una clara contestación del ideario y de las realizaciones del Surrealismo. Durante los años cuarenta el Surrealismo era una tendencia en crisis. Junto a la obra de algunos de sus grandes maestros convertidos en clásicos de la renovación artística de nuestro siglo, algunos de sus planteamientos todavía tenían un cierto eco en la obra de epígonos o jóvenes artistas que se iniciaban en la vanguardia. Sin embargo, si el Surrealismo presentaba claros síntomas de su agotamiento como tendencia, su ideario permanecía, aunque no de forma ostensible, en numerosas cuestiones y planteamientos que tendrían su proyección en nuevas tendencias de la pintura.

El Informalismo irrumpió como una tendencia que aparentemente era una variante de la abstracción en clara contraposición con las tendencias figurativas, entre las que ocupaba un lugar privilegiado el Surrealismo. También se consideró, a tenor de la denominación de alguna de sus modalidades, como Expresionismo abstracto. A pesar de todo, los fundamentos ideológicos del Informalismo - como luego sucederá con el Pop Art- presentaban una clara derivación de la ideología y de las tensiones surrealistas.

Uno de los problemas que trazan un hilo conductor entre el Surrealismo y el Pop Art ha sido la obsesión por desentrañar nuevos valores del objeto. Tanto una tendencia como otra tienen de común su carácter figurativo y el valor conferido a la representación como reacción frente a la abstracción. Los primeros inicios de la pintura surrealista, entre la que debemos plantear las evasiones metafísicas de Chirico, surgieron, independencia de su inmersión en el inagotable mundo de lo onírico y de la valoración de otros sentidos de la realidad, como una recuperación del sistema de representación. Es evidente que en las dos primeras décadas del siglo XX las vanguardias históricas, el Expresionismo y el Fauvismo, el Cubismo y el Futurismo, la abstracción de Kandinsky, el Neoplasticismo y las tendencias constructivistas y el Dadaismo habían planteado una destrucción del sistema figurativo y una experimentación de una serie de valores plásticos puros. Frente a ello, en los años veinte surgió el valor de lo onírico, el azar y la espontáneidad propuesta por el Surrealismo que confería una importancia relevante a la representación y a los nuevos valores derivados de la manipulación de la realidad y el objeto. Algo que habían 
planteado los dadaistas o Duchamp en sus reade-made pero que ahora iniciaba su andadura como sistema.

En 1924, André Breton, en el Primer manifiesto del Surrealismo, propugnaba la superación de las formas «lógicas» y convencionales de entender lo real para acceder a un nuevo sentido de la realidad libre de los usos y prácticas convencionales. Las imágenes con objetos contrastados y con realidades sumidas en un proceso de metamorfosis dominaron el arte de entreguerras. De ahí que, la irrupción vigorosa de la abstracción informalista en los años posteriores a la segunda Guerra mundial apareciese como una reacción frente a estas insistencias figurativas. La idea de la vanguardia pasó a identificarse con la abstracción. Sin embargo, la ruptura que suponía este nuevo lenguaje no fue total pudiéndose registrar en él no pocas deudas con la tradición surrealista hasta el punto de que en muchos casos la revolución informalista se gestó como una evolución surgida «desde dentro» del universo surrealista. En este sentido, fueron muchos los artistas informalistas, como Viola o Saura, que se iniciaron en su juventud en el ideario surrealista. En Barcelona, por ejemplo, aparecía en septiembre de 1948 el primer número de la revista Dau al Set, grupo que agrupaba a poetas y pintores como Joan Brossa, Arnau Puig, Tapies, Cuixart, Tharrats ,Ponç y el crítico Cirlot de formación claramente surrealista. Pues, en muchos casos la revolución informalista fue, en realidad, una evolución hacia nuevos planteamientos plásticos desarrollada desde «adentro» de la ideología del Surrealismo.

Después de 1945 el Surrealismo, como tendencia y como grupo, era un movimiento disperso y en crisis. Sin embargo, el Surrealismo había sido mucho más que un movimiento pictórico. Fue una actitud ante la vida que se proyectó en numerosos campos. Fue, también una ideología y una ética de la que el movimiento surrealista de entreguerras había sido solamente una de sus múltiples posibilidades pero cuyo espíritu no había muerto ni había agotado otras muchas vías de expresarse plásticamente. André Bretón no había planteado en sus manifiestos una definición normativa de la actitud surrealista ante la pintura Su manifiesto fue una declaración de principios y no un enunciado de planteamientos plásticos concretos. Lo que los pintores surrealistas como Magritte, Tanguy, Ernest o Dalí llevaron a la práctica fueron solamente algunas de las infinitas posibilidades de la opción surrealista elegidas libremente por ellos. De ahí, que la crisis del Surrealismo de los años cuarenta sólo fuera el agotamiento de estas actitudes y no la vigencia de una forma de actuar, sentir, vivir, entender el arte y la existencia que tras cinco años de guerra asumía nueva 
vigencia frente a la «lógica» de la ciencia, la economía, la política y la forma convencional de mirar el mundo.

Otro punto de conexión entre el Surrealismo y la abstracción lo constituye la personalidad de Paul Klee a través de la profunda influencia que ejerció su pintura en numerosos artistas de los años cuarenta y cincuenta. La intencionada ambigüedad entre abstracción y figuración de su pintura, el valor de lo primitivo como forma de afirmar un arte sin normas académicas, le convirtió en un modelo válido para numerosos pintores que en los años cuarenta y cincuenta iniciaban su aventura en la vanguardia. Klee realizó tanto obras abstractas como figurativas, pero en todas ellas late un pulso de primitivismo entendido como una recuperación esencial de lo primario desligada de los convencioalismos del mundo de la lógica. Otro caso similar lo constituye la obra de Miró cuya ambigüedad entre lo abstracto y lo figurativo y su entronque con el Surrealismo desarrollaron un papel ejemplar. Pues ambos pintores, que tuvieron una relación con el Surrealismo, fueron abstractos a la vez; a ambos les preocupó

Figura 1. DALI, 1933

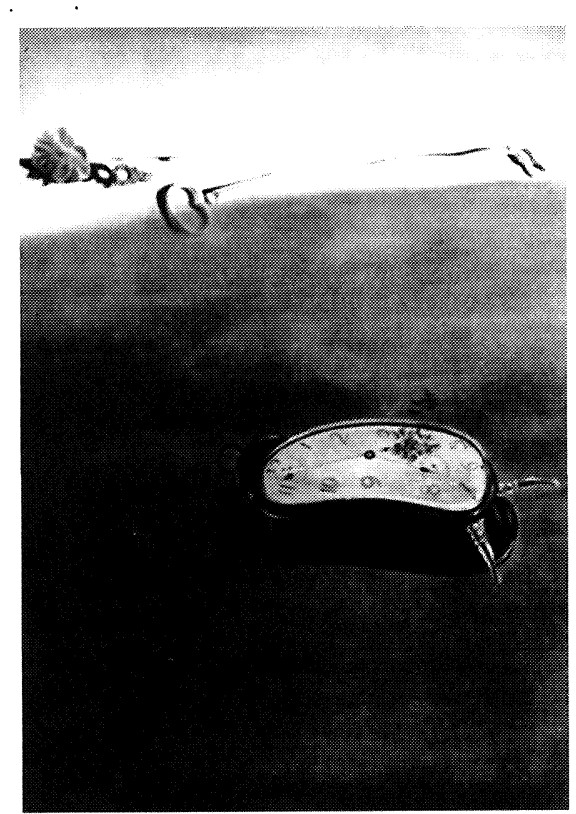


FIGURA 2. MAGRITTE (1898) «Il guaritore»

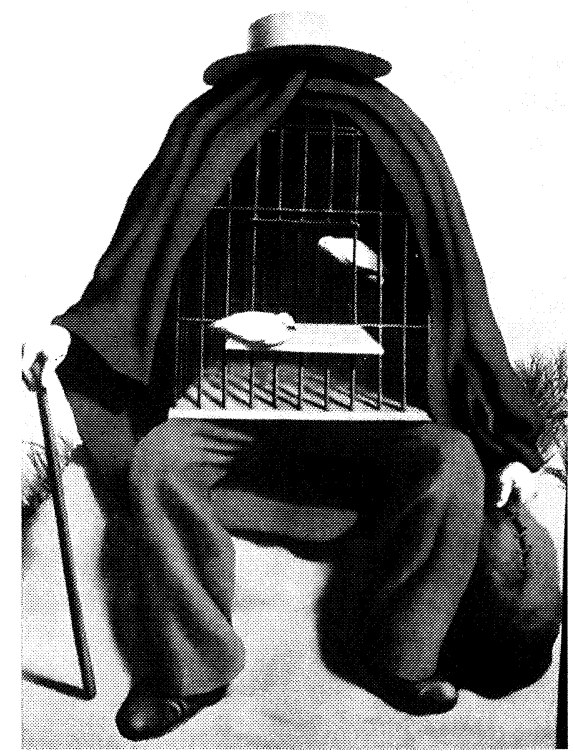

FIGURA 3. BURRI, Rojo en combustión plástica (1957)

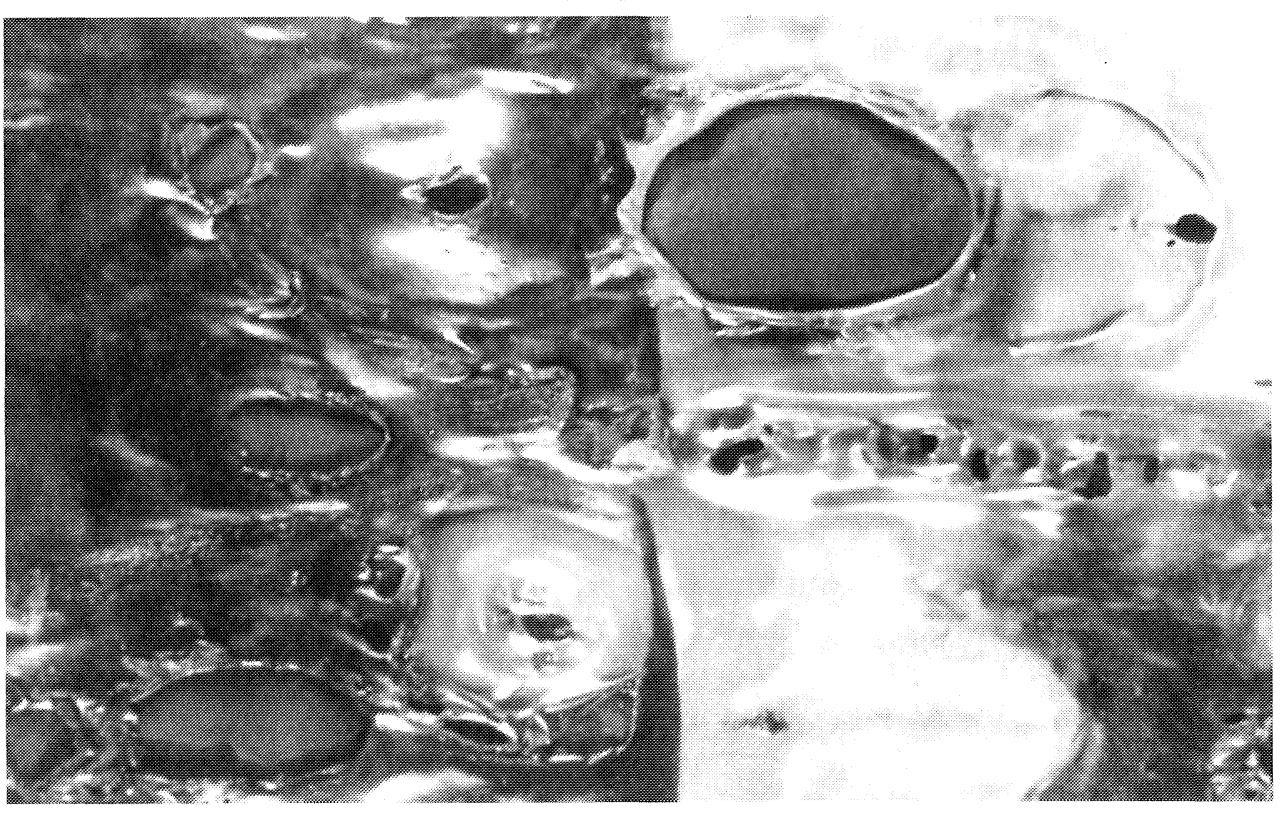


el valor primario de lo primitivo como expresión libre de la magia de la creación planteada desde un estado prelógico. Es decir, valores que los informalistas, tanto los pintores de materia como los gestuales o de acción, consideraron como los fundamentos de su pintura. Manolo Millares, por ejemplo, a partir de 1949 , a raíz de sus primeras «pictografías», experimentó la influencia de Paul Klee y Miró y se sintió atraido por el primitivismo de determinados elementos autóctonos canarios. Un primitivismo que, como referencia anticonvencional, tuvo una proyección figurativa en los graffiti, de Jean Dubuffet: monigotes e imágenes espontáneas formadas por el aparente efecto casual de los signos.

En este sentido, los informalistas identificaron la gestualidad con primitivismo, y con una caligrafía de lo espontáneo como hallamos en obras de Georges Mathieu desde los años cuarenta. Mathieu, con sus caligrafías creía lograr el imaginario de alcanzar una relación directa entre impulso y resultado sin mediaciones de la lógica y los factores que influyen en el proceso. Lo cual resulta evidente que se hallaba en la más clara tradición del automatismo surrealista aunque con ello llegase a unos resultados completamente distintos. Lo mismo que Jackson Pollock, en su pintura de acción desarrollaba una correspondencia directa entre el impulso y el resultado. Si formalmente se lograban unos resultados que rompían con los desarrollos preexistentes de la vanguardia desde un punto de vista ideológico es evidente que L'Informel, nombre utilizado por Mathieu en 1951 en su «Boquejo de una embriología los signos» (Esquisse d'une embryologie des signes), hundía sus raíces en las ideas y aspiraciones surrealistas.

Pero no solamente los signos, sino la materia, entendida como nuevo objeto, fue una experiencia que tiene sus orígenes teóricos en el valor del objeto surrealista. Se trata no de una materia representada, sino de la presentación misma de la materia como objeto plástico. Una de las primeras experiencias en este sentido, los Otages de Jean Fautrier, iniciaron el descubrimiento de una nueva realidad, de una realidad «otra» que entraba en competencia con la naturaleza. Los muros de Tapies, las arpilleras de Burri y Millares, la madera de Lucio Muñoz o el lienzo rasgado de Fontana, crearon la plasticidad de una realidad desapercibida, inédita y sugerente.

A principios de los años sesenta un crítico de arte, ante la impresionante proliferación de pintores informalistas pudo decir que, tras la ruptura inicial, el Informalismo puso al alcance de todos los subconscientes la posibilidad de ser pintor. Y, en efecto, lo que en un momento fue una actitud y un lenguaje de ruptura pronto se convirtió 
en unos usos acedemicistas y reiterativos. Ninguna tendencia de nuestro siglo tuvo un mayor número de cultivadores ni tampoco una proyección tan universal como el Informalismo. De ahí, que su crisis no se produjera por una indagación de sus propuestas llevada hasta sus últimas consecuencias por los descubridores de la tendencia sino por la saturación de sus infinitos cultivadores. Sin embargo, debido al carácter abstracto del informalismo, se supuso que esta crisis era debida al agotamiento de la abstracción cuando en realidad procedía del uso reiterativo de un mismo lenguaje.

Figura 4. Cruz de Castro: Trapo colgado (1964)

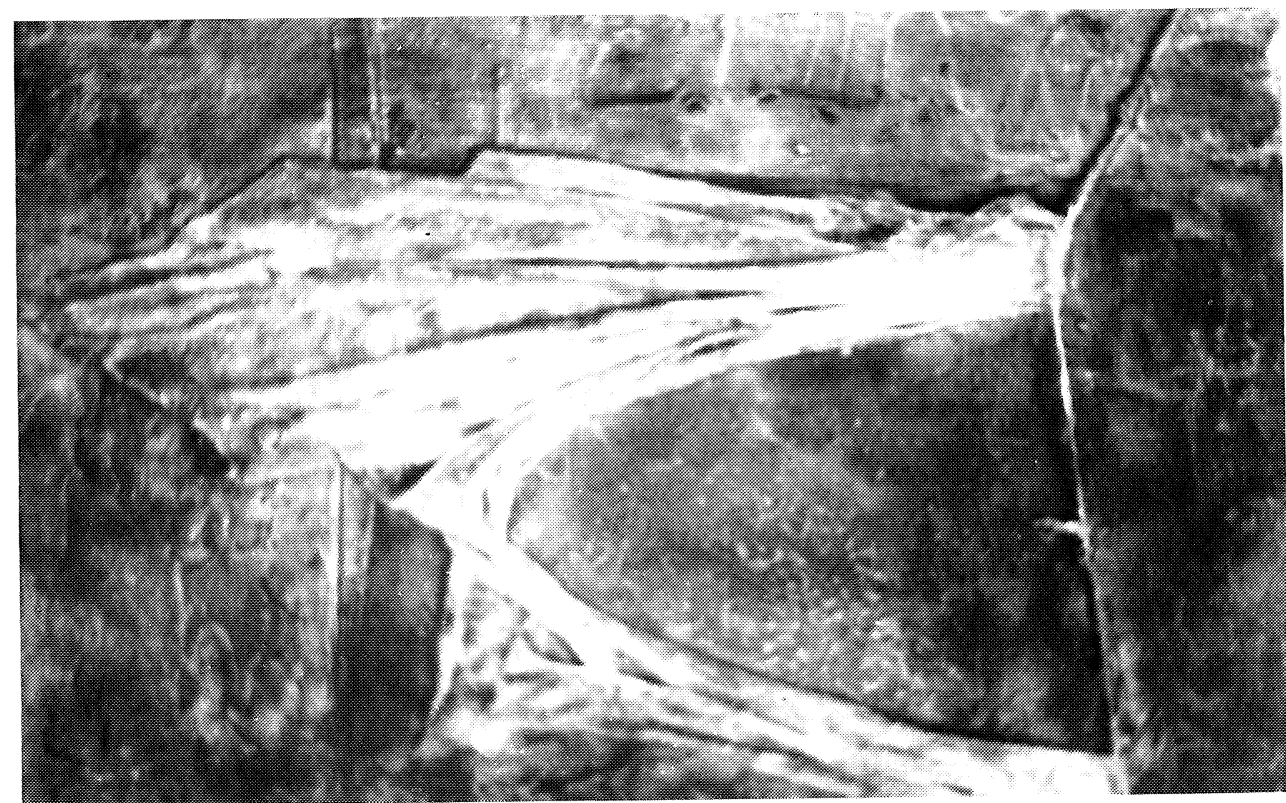

A este respecto, deja de ser paradójica la persistencia de la dicotomía establecida entre abstracción y la figuración como si bajo la noción de figuración pudieramos agrupar todas las tendencias figurativas del arte contemporáneo y bajo la abstracción todo lo que sea representativo. Muchas tendencias, como la Action Painting y los constructivismos fueron decididamente abstractas; otras, como los realismos y el Pop Art claramente figurativas. Sin embargo, no siempre 
ambos conceptos pueden utilizarse como manifestaciones antitéticas sino complementarias que, en muchos casos, presentan numerosos rasgos en común.

La irrupción del Pop Art y su implantación no se debió a que era un arte figurativo sino a que ofrecía contenidos y un lenguaje nuevo frente al esteticismo repetitivo a que había llegado el Informalismo. La abstracción y la figuración no encarnan por sí mismas ninguna tendencia, pues son medios, e instrumentos con los que desarrollar las ideas más dispares como sucede con la rigurosa geometría de las abstracciones de Mondrían y los irrepetibles girones vitales de Pollock, o entre la expresividad figurativa de Appel o las racionalizadas representaciones de Juan Gris. De ahí, que existan con frecuencia mayores analogías entre determinadas obras asbtractas con otras figurativas y viceversa que entre diferentes tendencias de la abstracción y entre diversas corrientes figurativas. En numerosas ocasiones la figuración se ha separado mucho más de la realidad que la abstracción mientras que muchos planteamientos de la abstracción han puesto de manifiesto un irrevocable compromiso con los problemas de la realidad.

La vigencia de Pop Art se debió a la novedad de su lenguaje y, sobre todo a algo que no interesó para nada a los informalistas: su carácter comunicativo. La utilización de imágenes con elementos prestados de los medios de comunicación de masas como aparecen en las obras de Andy Warhol, Robert Rauschenberg, Tom Wesselmann o Roy Lichtenstein o los objetos de consumo de Claes Oldenburg. Lo cual suponía, por otra parte, la indagación de un espectro olvidado de la realidad que pone de manifiesto, una vez más, la constante búsqueda de los artistas contemporáneos para descubrir los innumerables valores del objeto. 